\title{
A metátese na aquisição da escrita: simetrias e assimetrias entre fonologia e ortografia
}

\section{Metathesis on writing acquisition: symmetries and asymmetries between phonology and orthography}

\author{
Lissa Pachalski* \\ Universidade Federal de Pelotas, Pelotas, RS, Brasil \\ Ana Ruth Moresco Miranda* \\ Universidade Federal de Pelotas, Pelotas, RS, Brasil
}

\begin{abstract}
Resumo: Este estudo aborda dados de escrita infantil seguindo uma linha de investigação que se caracteriza por eleger o erro (orto)gráfico como principal objeto de análise, tratando-o como uma potencial pista reveladora do conhecimento em construção pelas crianças acerca da estrutura de sua língua, sobretudo da camada fonológica. Situado neste domínio teórico, o artigo explora a grafia da metátese de consoantes em textos de crianças em período de aquisição da escrita, a fim de contribuir para a discussão sobre o fenômeno, observando as relações simétricas e/ou assimétricas existentes entre as metáteses produzidas especialmente no período de aquisição fonológica e aquelas manifestas nas escritas iniciais. A análise dos dados reforça aspectos influentes já salientados por outros pesquisadores com relação à metátese, como a natureza dos segmentos envolvidos, a estrutura silábica e seu grau de complexidade, e a incerteza representacional ligada à nasalidade em coda medial e à segmentação de palavras gráficas. Fatores externos à fonologia da língua também foram observados enquanto possibilidades para a motivação do fenômeno na escrita, particularmente traçado de letra e hipersegmentação de palavras, aspectos que dizem respeito a conhecimentos notacionais, também constitutivos da aprendizagem do sistema de escrita, e que parecem interagir com as variáveis de natureza fonológica, apontando para as assimetrias entre fonologia e ortografia.
\end{abstract}

Palavras-chave: Metátese. Aquisição da Escrita. Fonologia e Ortografia. Erro (orto)gráfico.

\begin{abstract}
This study approaches children's writing data following a research line which is distinguished by electing the (ortho)graphic error as its main analysis object, treating it as a potential revealing clue of the knowledge in construction by children concerning the structure of their mother tongue, mainly on the phonological layer. In this theoretical domain, the article explores consonant metathesis' spelling in texts of children in their writing acquisition phase, seeking to contribute to the discussion about the phenomenon, observing existing symmetrical and/or asymmetrical relations between the metathesis produced especially in the phonological acquisition period and those manifested on early writings. The data analysis reinforces influential aspects already highlighted by other researchers regarding metathesis, such as the nature of the segments
\end{abstract}

\footnotetext{
* Mestranda do Programa de Pós-Graduação em Letras, Centro de Letras e Comunicação, Universidade Federal de Pelotas, Pelotas, RS, Brasil; pachalskil@gmail.com

** Professora adjunta, Faculdade de Educação, Universidade Federal de Pelotas, Pelotas, RS, Brasil; anaruthmmiranda@gmail.com
} 
involved, the syllabic structure and its degree of complexity, and the representational uncertainty associated within nasality on the medial coda and word segmentation. External factors to language phonology were likewise observed as possibilities for the motivation of the phenomenon on writing, particularly calligraphy and word hypersegmentation, aspects that relates to notational knowledge, also constitutive of the writing system learning and which seems to interact with variables of phonological nature, pointing to asymmetries between phonology and orthography.

Keywords: Metathesis. Writing Acquisition. Phonology and Orthography. (Ortho)graphic error.

\section{INTRODUÇÃo}

Este estudo aborda dados de escrita infantil seguindo uma linha de investigação que se caracteriza por eleger o erro (orto)gráfico ${ }^{1}$ como principal objeto de análise, tratando-o como uma potencial pista reveladora do conhecimento em construção pelas crianças acerca da estrutura de sua língua, sobretudo da camada fonológica (cf. Abaurre, 1988, 1991b, 2001; Cunha, 2004, 2010; Adamoli, 2012; Ney, 2012; Miranda, 2010, 2014).

Ideias implicadas nestes estudos, tais como as de que a escrita inicial incide sobre a gramática do aprendiz e os erros (orto)gráficos revelam aspectos do funcionamento fonológico da língua, sustentam-se em alguns pressupostos, tais como apresentados em Miranda (2014): (i) a aquisição da escrita como integrante do processo mais amplo de aquisição da linguagem (Abaurre, 1991a), o qual é regulado pela capacidade inata que as crianças possuem para a construção de gramáticas (Chomsky, 1965); (ii) a concepção de erro sob uma interpretação psicogenética - neste âmbito, o erro (orto)gráfico -, entendido como uma forma capaz de revelar as hipóteses do sujeito que interage com um novo objeto de conhecimento, a saber, o sistema de escrita alfabética (Piaget, 1971; Ferreiro; Teberosky, 1999); e (iii) a ideia de que a compreensão dos princípios da escrita alfabética cria condições para a atualização do conhecimento fonológico adquirido (Miranda, 2012).

Situado neste domínio teórico, este artigo explora a grafia da metátese de consoantes em textos de crianças em período de aquisição da escrita, a fim de contribuir para a discussão em torno do fenômeno, observando as relações, simétricas ou assimétricas, entre as metáteses produzidas especialmente no período de aquisição fonológica e aquelas manifestas nas escritas iniciais.

A hipótese de partida é a de que a motivação dos erros relacionados à metátese na escrita seja predominantemente fonológica, de forma que as variáveis selecionadas para a análise, de natureza linguística, mostrem-se pertinentes para sua descrição e exploração. A hipótese é sustentada, em grande medida, por aquilo que vários estudos

\footnotetext{
1 "O uso de parênteses tem como objetivo demarcar a diferença existente entre erros relacionados às regras do sistema ortográfico propriamente dito, os quais envolvem as relações múltiplas entre fonemas e grafemas, definidas contextual ou arbitrariamente, e aqueles produzidos na fase inicial do desenvolvimento da escrita, muitas vezes motivados por questões representacionais ou ainda por influência da fala, isto é, referentes ao funcionamento fonológico da língua” (Miranda, 2014, p. 47).
} 
realizados pelo GEALE ${ }^{2}$ vêm apresentando ao analisarem dados de escrita vinculados a textos que compõem o BATALE ${ }^{3}$, ou seja, de que os erros de natureza fonológica são sempre mais numerosos em relação àqueles de natureza ortográfica ${ }^{4}$ (cf. Miranda, 2013 e Pachalski et al., 2015a, que analisam diferentes estratos do BATALE e chegam a resultados similares).

O artigo está estruturado da seguinte forma: primeiro, é realizada uma caracterização do fenômeno, à luz de estudos que se dedicaram a analisá-lo sob a perspectiva fonológica (Hume 2001; 2004; Hora; Telles; Monaretto, 2007; Zitzke, 1998, 2001; Lamprecht, 2002; Redmer, 2007) e da aquisição da escrita (Coelho, 2016; Pachalski et al., 2015b; Pachalski; Miranda, 2016, 2017); depois, os procedimentos metodológicos são descritos, seguidos da apresentação e discussão das grafias com metátese extraídas de escritas iniciais; por fim, são expostas as considerações finais.

\section{CARACTERIZAÇÃo DO FENÔMENO}

A metátese, que é caracterizada, nos termos de Hume (2001, p. 1, tradução nossa), como um "processo no qual, em certas línguas e sob certas condições, a ordem linear de sons esperada é invertida" , é um fenômeno pouco estudado, ainda que recorrente nas línguas em geral, tanto sincrônica quanto diacronicamente (Hume, 2001, 2004; Hora; Telles; Monaretto, 2007), e na aquisição da fala (Zitzke, 1998, 2001; Lamprecht, 2002; Redmer, 2007). Para Hume (2001), a escassez de estudos sobre a metátese pode ser decorrente de uma percepção errônea da comunidade científica, que o encara como fenômeno "esporádico e irregular, restrito a erros de performance, à linguagem infantil ou à troca de sons" (Hume, 2001, p. 1, tradução nossa). Com relação ao estudo da metátese no processo de aquisição da escrita, a escassez é ainda maior. À exceção do estudo de Coelho (2016), uma dissertação sobre transposições na

${ }^{2}$ O GEALE (Grupo de Estudos sobre Aquisição da Linguagem Escrita) é um Grupo de Pesquisa vinculado ao CNPq, criado em 2001 e ligado ao programa de Pós-Graduação em Educação da Faculdade de Educação da UFPel.

3 O BATALE (Banco de Textos de Aquisição da Linguagem Escrita) atualmente possui em seu acervo cerca de 7 mil textos produzidos por crianças dos anos iniciais do ensino fundamental. Esse conjunto de textos está dividido em 8 estratos, resultantes de coletas realizadas de 2001 a 2015 em diversas escolas da rede pública de ensino e uma da rede particular. Desses textos, é extraído o principal objeto de estudo e análise do GEALE: o erro (orto)gráfico.

${ }^{4}$ Os erros de natureza ortográfica são aqueles que estão ligados sobretudo às relações múltiplas entre fonemas e grafemas (Lemle, 1987), as quais regem boa parte do sistema ortográfico do português. Eles podem estar relacionados ou à arbitrariedade do sistema ou à presença de contextos que restringem a utilização de certos grafemas. Assim, uma forma como 'xata' para 'chata' está vinculada à primeira tipologia, visto que a representação de []] na escrita não é previsível pelo contexto (é arbitrária), podendo ser grafada com uso de 'x' ou 'ch'. Já uma grafia como 'tera' para 'terra' está relacionada à segunda tipologia, pois a representação de $[\chi]$ é passível de inferência através da observação de uma regra contextual básica, qual seja, a de que $[\chi]$ deve ser grafado com 'rr' quando estiver em posição intervocálica.

5 “[...] [Metathesis is the] process whereby in certain languages, under certain conditions, sounds appear to switch positions with one another" (Hume, 2001, p. 1).

6 " [...] [the view of] metathesis as sporadic and irregular, restricted to performance errors, child language or sound change" (Hume, 2001, p. 1). 
escrita de crianças dos anos iniciais de escolarização, não foram encontradas outras fontes ${ }^{7}$.

De todo modo, nos estudos existentes, sejam de aquisição, sincronia ou diacronia, a metátese é assumida, de forma geral, como um processo caracterizado pelo reordenamento de sons ou traços dentro de uma sequência fonológica, conforme a definição de Hume (2001) apresentada anteriormente. A alteração sequencial poderá envolver sílabas ou segmentos, dando origem a dois grupos de metáteses: (i) silábicas, menos frequentes, nas quais sílabas inteiras podem trocar de lugar com outras e o resultado são formas tais como [ka.se.'pa.tfi] para o item lexical 'capacete', por exemplo, e (ii) segmentais, as quais podem ser subagrupadas em segmentais simples, quando envolvem o deslocamento de um segmento apenas, como em ['per.to] para 'preto', e segmentais duplas, nas quais dois segmentos trocam de posição mutuamente, como em ['ma.ni.ka] para 'máquina'. No presente estudo, foram computados apenas dados de metáteses segmentais (simples e duplas). Ainda no subgrupo das metáteses segmentais simples, é relevante observar o domínio dos deslocamentos dentro da palavra fonológica, o que leva a dois tipos de agrupamentos, ambos observados neste estudo: intrassilábicas, quando o segmento permanece na sílaba de origem, como em ['con.fro.tu] para 'conforto', e intersilábicas, quando o segmento é movido para outra sílaba dentro da palavra, como em ['pros.te.tu] para 'protesto'.

Algumas diferenças, no entanto, devem ser observadas nos diferentes domínios em que a metátese ocorre. Assim sendo, nas seções que seguem, a metátese será caracterizada com mais detalhes em sua ocorrência na sincronia, na diacronia, na aquisição da fala e na aquisição da escrita.

\section{1 $\mathrm{Na}$ sincronia}

Hume (2001), que em seus estudos busca observar padrões de metátese em diferentes línguas, afirma que "enquanto a metátese é menos comum que processos como assimilação e omissão de sons, ela pode, ainda assim, ocorrer como um processo fonológico sincrônico e regular, em uma ampla gama de línguas"8 (Hume, 2001, p. 2). Segundo a autora, para compreender os padrões de ocorrência da metátese encontrados em línguas distintas, é necessário considerar dois fatores que atuam conjuntamente: a natureza fonética dos sons envolvidos e o conhecimento que o falante/ouvinte tem a respeito dos padrões de sons da sua língua nativa, bem como a frequência com que eles ocorrem. Isso quer dizer que uma sequência de sons nãofamiliar para um falante/ouvinte de uma língua é uma candidata potencial a alvo do processo da metátese, ou seja, poderá sofrer um reordenamento conforme os padrões linguísticos mais comuns ao falante.

Nesse sentido, Hume (2004) faz duas afirmações interessantes: i) aprendemos a prestar atenção nas pistas fonéticas importantes para distinguir os elementos relevantes para a língua, e, ao mesmo tempo, ignorar aqueles que não o são; ii) processamos a palavra afetados por fatores como a frequência de sua ocorrência na língua, o número de palavras vizinhas foneticamente similares, a previsibilidade da

\footnotetext{
${ }^{7}$ Busca realizada no portal de periódicos e teses da CAPES (http://www.periodicos.capes.gov.br).

8 “[...] while metathesis is less common than processes such as assimilation and sound deletion, it can nonetheless occur as a regular synchronic phonological process in a wide range of languages" (Hume, 2001, p. 2).
} 
sequência de sons da palavra e o grau de familiaridade que temos com ela. Soma-se a isso, uma variável muito importante: a indeterminância do sinal, ou seja, um estado em que há informação insuficiente a respeito do input recebido, o que irá fazer com que o ouvinte acione - para dar conta do processamento - a sua experiência com as unidades incluídas na sequência sonora. Entrará em jogo também a natureza dos segmentos envolvidos (se são familiares ou não e se fornecem boas pistas acústicas ou encobrem informações relevantes).

Hora, Telles e Monaretto (2007), assumindo o modelo proposto por Hume (2001, 2004) para analisar a metátese na sincronia e na diacronia do Português Brasileiro (PB), sustentam a hipótese de que no PB a metátese é um fenômeno de status marcado sincronicamente, ocorrendo de forma majoritária nas variedades nãopadrão da língua ou em itens lexicais cuja mudança linguística já foi implementada. Além disso, também é regulada por variáveis linguísticas, como direcionalidade, posição de sílaba, restrições fonotáticas e contexto segmental, como ilustram os exemplos em (1), extraídos de Hora, Telles e Monaretto (2007):

(1)

$$
\begin{aligned}
& \text { la.gar.to } \rightarrow \text { lar.ga.to (preferência do movimento à esquerda, } \\
& \text { em metáteses intersilábicas) } \\
& \text { for.mi.ga } \rightarrow \text { fro.mi.ga (preferência do movimento na primeira sílaba da palavra, } \\
& \text { em metáteses intra e intersilábicas) } \\
& \text { lar.va } \rightarrow \text { *lra.va } \quad \text { (movimento restringido pela fonotática da língua, } \\
& \text { em metáteses intra e intersilábicas) } \\
& \text { for.ça } \rightarrow \text { fro.ça } \quad \text { (preferência do movimento quando a consoante seguinte } \\
& \text { à rótica for [+contínua], em metáteses intrassilábicas) }
\end{aligned}
$$

\section{2 $\mathrm{Na}$ diacronia}

Hora, Telles e Monaretto (2007) fazem uma descrição da metátese na diacronia do PB a partir de uma revisão bibliográfica sobre a história da língua e de uma análise de manuscritos oficiais desde o século XVII. A análise é sustentada pela Fonologia Evolucionária de Blevins e Garret (2004), cuja premissa é a de que regularidades diacrônicas exercem papel decisivo em padrões fonológicos atuais, o que, segundo os autores, auxilia na simplificação de modelos sincrônicos. Dessa maneira, mudanças sonoras, lexicalizadas sincronicamente, seriam causadas sobretudo por reinterpretações assentadas no sistema perceptual do ouvinte (Hora; Telles; Monaretto, 2007). Com relação à metátese, especificamente, Blevins e Garret (2004), em sua Fonologia Evolucionária, propõem uma tipologia como pode ser visualizada no quadro 1 :

Quadro 1 - Quadro dos tipos de metáteses, adaptado de Blevins e Garret (2004).

\begin{tabular}{cc} 
Ti力o de metátese & Exemplo \\
\hline Perceptual & per.gun.ta $\rightarrow$ pre.gun.ta \\
Compensatória & tá.bua $\rightarrow$ tau.ba \\
Coarticulatória & drik-pa- $\rightarrow$ dripka- grego \\
Auditiva & ask $\rightarrow$ aks - inglês \\
\hline
\end{tabular}


A análise de Hora, Telles e Monaretto (2007) sobre a metátese na história da língua portuguesa baseada na tipologia apresentada leva os pesquisadores a considerar que o fenômeno, diacronicamente, não estaria ligado a fatores sociais, pois é possível observar com frequência sua presença oscilante em textos oficiais, desde o século XVII, os quais são representativos da variedade padrão. Assim, a metátese mostra-se como regra variável e não como vinculada a uma variedade linguística mais estigmatizada. Além disso, tipologicamente são observadas metáteses de tipo perceptual e compensatória, isto é, ou envolve "traços de longa duração em cadeias multissegmentais que se espraiam sobre uma sequência inteira" como em [tru'se] para 'torcer' ou "é prosodicamente condicionada, o que significa que traços em uma sílaba fraca migram para uma sílaba forte" como em ['tawba] para 'tábua' (Hora; Telles; Monaretto, 2007, p. 180).

\section{3 $\mathrm{Na}$ aquisição da fonologia}

Com relação à ocorrência da metátese na aquisição da fonologia do $\mathrm{PB}$, três importantes estudos devem ser mencionados: Zitzke (1998, 2001), pioneiro no Brasil no que tange à descrição da metátese na aquisição; Lamprecht (2002), cuja abordagem está ancorada na Teoria da Otimidade (McCarthy; Prince, 1993), tomando como base os resultados de Zitzke (1998); e Redmer (2007), um estudo mais completo sobre o fenômeno, integrando aspectos descritivos e explicativos, à luz da Fonologia Autossegmental (Clements; Hume, 1995) e da Teoria da Otimidade, levando em consideração, também, contribuições de outros pesquisadores neste artigo citados.

Em comum entre as três autoras está a hipótese de que a metátese seria um processo particularmente motivado por estruturas silábicas complexas, de aquisição mais tardia, em especial CCV e CVC. Entretanto não necessariamente ocorre simplificação das estruturas, indicando a busca de uma estrutura menos marcada que a original, como inicialmente seria esperado. Há, por exemplo, manutenção de padrões silábicos complexos (como CCV para CCV, em [da'grãw] para 'dragão') ou mesmo complexificação desses padrões (como CVC para CCV, em ['vredzi] para 'verde'). Assim, Redmer (2007), motivada por observações de Lamprecht (2002) sobre a relevância do pé métrico para a ocorrência da metátese, procura verificar o que poderia estar motivando metáteses que fogem à tendência esperada. O que a autora observa é a atuação da variável tonicidade, uma vez que os segmentos são deslocados na ou para a sílaba proeminente dentro da palavra fonológica, ou seja, para aquela que porta o acento primário. Isso é observável nos casos recém exemplificados, [da'grãw] e ['vredzi], nos quais a líquida não-lateral é deslocada da posição átona para a tônica ou permanece na própria sílaba tônica.

Além do efeito de variáveis como a estrutura silábica e a tonicidade, Redmer (2007) constata que a natureza dos segmentos envolvidos pode ser relevante em casos de metáteses segmentais duplas, com estruturas silábicas não marcadas, onde dois segmentos trocam de posição entre si dentro da palavra (como CV para $\mathrm{CV}$, em ['namu] para 'mano'). Nesses casos, em particular, o traço [coronal] parece desempenhar um papel relevante, pois foi observada a tendência de pelo menos um dos onsets envolvidos serem preenchidos por uma consoante [coronal] "e, quando esse onset [coronal] migra para a direita, o onset seguinte, à direita, é também [coronal]" (Redmer, 2007, p. 45), como em [kofo'latfi] para 'chocolate'. 
Com relação à faixa etária em que o fenômeno ocorre no percurso de aquisição da fala em desenvolvimento típico, Zitzke (2001) e Redmer (2007) constatam que a metátese passa a ser observável a partir de 2 anos de idade estendendo-se até os 7 anos, em média. Para Redmer (2007, p. 51) "a ausência do processo de metátese, nas fases mais iniciais da aquisição da fonologia, ocorre porque os sistemas das crianças ainda não incluem as estruturas complexas". Com relação à frequência de ocorrência, Zitzke (2001) observa que a distribuição do processo se dá de forma heterogênea, isto é, sem uma concentração notável de ocorrência em alguma faixa etária específica, embora Redmer (2007) verifique em seus dados uma taxa de incidência mais alta entre 3 anos e 6 meses e 3 anos e 8 meses.

\section{$2.4 \mathrm{Na}$ aquisição da escrita}

Como mencionado na introdução (seção 1), se há pouca produção a respeito da metátese na literatura fonológica, na aquisição da escrita o quadro é ainda mais diminuto. Coelho (2016) é um dos raros estudos que analisa os dados de metátese na escrita inicial de crianças brasileiras. A autora, no entanto, o faz sem conectar os dados de escrita com a metátese encontrada na fala, o que a leva a designar o fenômeno como uma transposição ortográfica?.

De forma geral, Coelho (2016) verifica um predomínio de estruturas CVC e CV como resultado das metáteses, o que parece reforçar a ideia de as metáteses estarem ligadas, em boa medida, à busca pela redução de complexidade de estruturas silábicas. Em relação à tonicidade, a autora não encontra diferença estatisticamente significativa entre metáteses ocorridas em sílabas não-acentuadas e em sílabas acentuadas.

Além do estudo de Coelho (2016), uma série de pequenos estudos têm sido conduzidos no GEALE (cf. Pachalski et al., 2015b; Pachalski; Miranda, 2016, 2017) abordando a metátese nas escritas iniciais sob a perspectiva da interface entre fonologia e ortografia, os quais formam o substrato deste artigo. Neles, algumas pistas são apresentadas, as quais auxiliam a formular hipóteses iniciais sobre possíveis motivações para a metátese na aquisição da escrita. Os indícios apontados dizem respeito, sobretudo, à incidência das variáveis relacionadas à complexidade das estruturas silábicas e aos traços distintivos constitutivos dos segmentos envolvidos na metátese. Tonicidade e direcionalidade também foram fatores observados, mas apresentaram importância secundária.

Em um contexto mais amplo, cuja ênfase não se dá exclusivamente sobre o processo de metátese, Abaurre (2001) apresenta pistas importantes para se pensar processos que tenham a sílaba como domínio principal, tais como apagamento de líquida, apagamento de coda nasal e, claro, metátese. A autora sugere que tais fenômenos, na escrita, revelariam indícios de um processo de construção da hierarquia de constituintes silábicos pelas crianças, ou seja, um processo de aprendizagem e decisão, via análise da estrutura silábica, "sobre o número de segmentos que devem ser representados, bem como a posição que devem ocupar na estrutura das sílabas" (Abaurre, 2001, p. 75, grifos nossos). Deste modo, o desafio da criança durante a aquisição da escrita não diz respeito à incorporação de novas estruturas ao inventário fonológico, mas sim à análise daquelas já existentes, só que a partir de outro ponto de

\footnotetext{
${ }^{9}$ A partir daqui, mesmo quando se fizer referência a considerações de Coelho (2016), será utilizado o
} termo metátese para designar o fenômeno em foco. 
vista, isto é, do ponto de vista gráfico. Assim, ao voltar-se para a forma gráfica, a criança tem acesso mais direto à constituição interna das sílabas e de seus constituintes.

\section{Procedimentos metodológicos}

Os dados de escrita inicial, a partir dos quais é explorado o fenômeno da metátese, foram extraídos de 2024 textos que integram o primeiro estrato do Banco de Textos de Aquisição da Linguagem Escrita - BATALE (Miranda, 2001) -, compreendendo um universo de 157 grafias de palavras fonológicas nas quais foi verificada a ocorrência de alteração na ordem dos grafemas. Desse conjunto de dados, foram efetivamente analisados 116, sendo descartadas 41 grafias que continham metáteses de vogais e semivogais. A justificativa para o descarte é o tratamento diferenciado que os tipos de segmento, consonantais e vocálicos, exigem, o que acabaria excedendo o escopo deste artigo.

Os dados foram distribuídos de acordo a unidade fonológica atingida (no caso, apenas segmento), resultando em dois grandes grupos: metáteses segmentais simples e segmentais duplas ${ }^{10}$. Para o primeiro grupo, a variável de análise que se mostrou mais relevante foi estrutura silábica, com relação ao grau de complexidade, o que resultou em um subagrupamento: metáteses intrassilábicas e intersilábicas. Já para o segundo grupo, a variável mais relevante foi estrutura segmental, relativa a traços de ponto de articulação (dorsal, coronal e labial), além de fatores secundários como segmentação gráfica, nasalidade, acento/pé métrico e traçado de letra.

O parâmetro para a definição de grau de complexidade de estruturas silábicas aqui utilizado está ancorado em Lamprecht et al. (2004), que propõem uma escala para a aquisição das estruturas silábicas no $\mathrm{PB}: \mathrm{CV}, \mathrm{V}<\mathrm{CVV}<\mathrm{CVC}, \mathrm{VC}<\mathrm{CCV}<$ $\operatorname{CCVC}(\mathrm{C})$. Segundo as autoras, o padrão silábico adquirido mais precocemente é também aquele mais simples, constituído apenas de vogal ou consoante + vogal. $\mathrm{O}$ mais complexo, em contrapartida, é aquele que apresenta mais variações na composição silábica e que é, consequentemente, adquirido mais tardiamente, constituído tanto de onset quanto de rima que podem ser ramificados, com 3 ou mais constituintes.

Os 116 dados foram organizados em planilhas de Excel de acordo com as variáveis recém explicitadas, o que permitiu não somente a estocagem dos dados mas também sua análise parcial, através de funcionalidades disponibilizadas pelo software, tais como aplicação de fórmulas, filtros e classificações.

\section{A METÁTESE NA AQUISIÇÃo DA ESCRITA: ANÁLISE E DISCUSSÃo DOS DADOS}

Inicialmente, os 116 dados de escrita foram distribuídos e organizados em duas grandes categorias: metáteses segmentais simples e segmentais duplas. A primeira diz respeito a metáteses que envolvem o deslocamento de um segmento apenas, como em 'codra' para 'corda' (figura 1); a segunda se refere àquelas que envolvem dois segmentos os quais realizam uma permuta posicional, isto é, trocas segmentais onde

${ }^{10}$ Lembrando, conforme referido na seção 1, que casos de metáteses silábicas não foram encontradas na amostra aqui analisada. 
um segmento ocupa a posição que o outro antes ocupava e vice-versa, como em 'porvafor' para 'por favor' (figura 2).

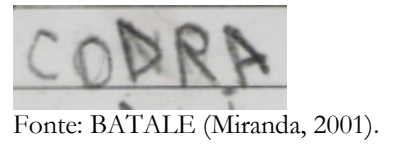

Figura 1 - Exemplo de metátese segmental simples: codra para 'corda'.

Grafia produzida por aluno de $1^{\mathrm{a}}$ série.

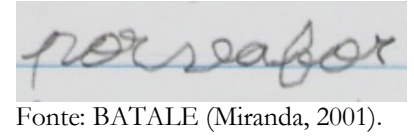

Figura 2 - Exemplo de metátese segmental dupla: porvafor ('por favor').

Grafia produzida por aluno de $4^{a}$ série.

Essa subdivisão inicial dos dados levou em conta especialmente considerações de Redmer (2007) que demonstram haver comportamentos e, consequentemente, motivações distintas dentro desses dois grupos de metáteses, especialmente ligadas à alteração ou não das estruturas silábicas envolvidas. A autora verificou que as metáteses segmentais simples em geral modificam a qualidade da estrutura silábica de destino, i. e., aquela que recebe o segmento deslocado. As segmentais duplas, por outro lado, não apresentam essa característica, uma vez que envolvem a permuta de dois segmentos que trocam mutuamente de posição silábica (ambos sempre ocupam ataque simples). Tais aspectos também puderam ser observados nos dados de escrita e serão explorados, em detalhe, na continuidade do artigo.

A tabela 1 apresenta como os dados distribuem-se quando considerados esses agrupamentos:

Tabela 1 - Distribuição dos dados nas categorias "segmental simples" e "segmental dupla".

\begin{tabular}{|c|c|c|}
\hline \multirow{2}{*}{ Tipo de metátese } & \multicolumn{2}{|c|}{ Frequência de ocorrência } \\
\hline & $N .^{o_{s}}$ absolutos & Percentual \\
\hline Segmental simples & 102 & $87,17 \%$ \\
\hline Segmental dupla & 14 & $12,82 \%$ \\
\hline Total & 116 & $100,00 \%$ \\
\hline
\end{tabular}

Os dados apresentados pela tabela 1 permitem observar que o número de metáteses segmentais simples na amostra é maior que o de segmentais duplas $(87,2 \%$ e $12,8 \%$, respectivamente). Esse percentual é bastante semelhante àquele encontrado por Zitzke $(1998,2001)$ e Redmer (2007), que verificam 85\% para segmentais simples e 15\% para segmentais duplas (valores em média).

Nas seções que seguem, 4.1 e 4.2, os dois grupos serão explorados em detalhe, levando em consideração, respectivamente, as variáveis estrutura silábica e estrutura segmental. 


\subsection{Metáteses segmentais simples}

É necessário ter em vista que a análise da variável estrutura silábica é possível somente em metáteses segmentais simples, isto é, aquelas que envolvem o deslocamento de um segmento apenas. Metáteses que envolvem dois segmentos (segmentais duplas), não têm condições, pela sua própria natureza, de alterar a qualidade de estrutura silábica, como se verá na seção seguinte (4.2).

A primeira consideração a se fazer sobre este grupo é que são observáveis dois tipos de comportamentos regulares relativamente ao movimento dos segmentos, os quais também são atestados na literatura de aquisição fonológica (Zitzke, 2001; Lamprecht, 2002; Redmer, 2007), conforme apresenta a tabela 2, a seguir:

Tabela 2 - Distribuição dos dados de metáteses segmentais simples conforme as sílabas envolvidas no deslocamento dos segmentos.

\begin{tabular}{cccc} 
Tipo de metátese & \multicolumn{2}{c}{ Frequência de ocorrência } & Exemplo \\
\cline { 2 - 4 } segmental simples & $N^{\text {os }_{\text {. }} \text { absolutos }}$ & Percentual & \\
\hline Intrassilábica & 72 & $70,6 \%$ & lugar $\rightarrow$ lugra \\
Intersilábica & 30 & $29,4 \%$ & trago $\rightarrow$ tagro \\
\hline Total & 102 & $100,00 \%$ &
\end{tabular}

Em um subgrupo, observa-se que o segmento deslocado no processo de metátese permanece na sílaba da qual originalmente faz parte, alterando apenas a estrutura interna local (metátese intrassilábica); em outro, o segmento deslocado migra em direção a outra sílaba dentro da palavra, gerando alteração na estrutura tanto da sílaba da qual originalmente fazia parte, quanto daquela à qual se destina (metátese intersilábica).

A tabela evidencia uma tendência de as metáteses segmentais simples envolverem apenas uma sílaba, alterando o ordenamento de seus constituintes internos, isto é, de serem intrassilábicas. Zitzke (2001), Lamprecht (2002) e Redmer (2007) são unânimes em apontar maior frequência de metáteses intersilábicas nos corpora com que trabalharam, o que torna o resultado apresentado na tabela 2 contrário ao que é atestado nos estudos de aquisição da fonologia, revelando, neste ponto, uma assimetria entre dados de fala e de escrita.

Entretanto, para entender o que esse tipo de caracterização pode implicar, é necessário olhar com maior detalhe o que ocorre em cada um dos subgrupos. Quais os tipos de estruturas silábicas envolvidas? Qual o resultado em termos de ordenamento dos constituintes silábicos gerado pela metátese? Quais as implicações de tais resultados?

\subsubsection{Metáteses intrassilábicas}

Nesta seção, a fim de buscar respostas às perguntas recém formuladas, são examinados os dados relativos às metáteses intrassilábicas, aquelas que mobilizam apenas uma sílaba da palavra fonológica, e que necessariamente geram um rearranjo dos constituintes silábicos locais. A tabela 3 apresenta resultados relativos à qualidade das estruturas silábicas envolvidas nos casos de metáteses desse grupo específico: 
Tabela 3 - Distribuição dos dados de metáteses intrassilábicas conforme a modificação gerada na sílaba portadora do segmento deslocado.

\begin{tabular}{|c|c|c|c|c|}
\hline \multirow{2}{*}{$\begin{array}{c}\text { Estrutura } \\
\text { original da silaba } \\
\text { alvo da metátese }\end{array}$} & \multirow{2}{*}{$\begin{array}{c}\text { Estrutura } \\
\text { da silaba } \\
\text { após a metátese }\end{array}$} & \multicolumn{2}{|c|}{ Frequência de ocorrência } & \multirow[b]{2}{*}{ Exemplo } \\
\hline & & $N .^{o_{s}}$ absolutos & Percentual & \\
\hline CCV & CVC & 27 & $37,5 \%$ & brabo $\rightarrow$ barbo \\
\hline CVC & $\mathrm{CCV}$ & 19 & $26,4 \%$ & adormecida $\rightarrow$ dromesida \\
\hline CCVC & $\begin{array}{l}\text { CVC } \\
\text { CVCC }\end{array}$ & $\begin{array}{l}9 \\
8\end{array}$ & $\begin{array}{l}12,5 \% \\
11,1 \%\end{array}$ & $\begin{array}{l}\text { grande } \rightarrow \text { gerde } \\
\text { triste } \rightarrow \text { tirste }\end{array}$ \\
\hline $\mathrm{VC}$ & $\mathrm{CV}$ & 6 & $8,3 \%$ & espada $\rightarrow$ sepada \\
\hline $\mathrm{CV}$ & $\begin{array}{l}\mathrm{VC} \\
\mathrm{CVC}\end{array}$ & $\begin{array}{l}2 \\
1\end{array}$ & $\begin{array}{l}2,8 \% \\
1,4 \%\end{array}$ & $\begin{array}{c}\text { se perdeu } \rightarrow \text { espedeu } \\
\text { segurança } \rightarrow \text { siguramas }\end{array}$ \\
\hline $\mathrm{Tc}$ & & 72 & $100,00 \%$ & \\
\hline
\end{tabular}

Dos dados apresentados na tabela 3, depreende-se que, na maior parte dos casos, a metátese intrassilábica se origina de uma sílaba considerada complexa, tendo em vista o parâmetro utilizado (ver seção 3), com onset ou rima ramificados, isto é, com 3 ou mais segmentos. Exceções a essa tendência são muito poucas: 3 metáteses são originárias de sílaba CV. Note-se que as sílabas resultantes são também complexas. Nesse sentido, de fato, ambientes em que estruturas silábicas complexas estejam presentes parecem ser favoráveis à ocorrência da metátese na escrita, indo ao encontro daquilo que é verificado na aquisição da fonologia (Zitzke, 1998, 2001; Lamprecht, 2002; Redmer, 2007) e também ao que Coelho (2016) aponta para a escrita, constatando incidência maior do processo em sílabas CVC e CCV.

Os resultados obtidos para a metátese intrassilábica suscitam ainda outra pergunta, qual seja: as sílabas resultantes seriam menos complexas que as originais, ao ser considerada a escala de complexidade silábica apresentada na seção 3? A metátese intrassilábica tem a tendência de desencadear processos de perda ou aumento de complexidade silábica?

A hipótese de partida nos estudos fonológicos é a de que as metáteses, de forma geral, apresentariam preferencialmente tendência à formação de estruturas silábicas mais simples ${ }^{11}$ que as originais, o que é atestado nos estudos de Zitzke (1998, 2001), Lamprecht (2002) e Redmer (2007). Casos que contrariam essa expectativa, cuja frequência de ocorrência seria bastante reduzida, seriam aqueles que geram aumento ou manutenção de complexidade. Coelho (2016), para a escrita, também aponta para

${ }_{11}$ A noção de simplicidade está relacionada à ordem de aquisição, conforme explicitada na seção 3 deste artigo. 
uma tendência de redução de complexidade estrutural promovida pela metátese, assim como Abaurre (2001). A fim de melhor verificar essa hipótese, os dados de escrita, considerando o que foi apresentado na tabela 3, foram redistribuídos conforme a tabela 4:

Tabela 4 - Distribuição dos dados de escrita conforme tipo de resultado das metáteses intrassilábicas em termos de complexidade da estrutura silábica (perda ou aumento de complexidade).

\begin{tabular}{cccc}
$\begin{array}{c}\text { Tipo de processo } \\
\text { (complexidade silábica) }\end{array}$ & \multicolumn{2}{c}{ Frequência de ocorrência } & Exemplo \\
\hline N. ${ }^{\text {s }}$ absolutos & Percentual & livre $\rightarrow$ liver \\
\hline $\begin{array}{c}\text { Perda de complexidade } \\
\text { Aumento de } \\
\text { complexidade }\end{array}$ & 50 & $69 \%$ & persegui-lo $\rightarrow$ precigilo \\
\hline Total & 22 & $31 \%$ & $100 \%$
\end{tabular}

A tabela 4 mostra que há uma preferência por deslocamentos segmentais que desencadeiem perda de complexidade de estruturas silábicas, os quais totalizam $69 \%$ de ocorrência. Casos de aumento da complexidade apresentam 31\% de ocorrência. Este resultado sugere uma simetria com relação à hipótese sustentada nos estudos de aquisição da fala, indicando que, ao menos no que se refere às metáteses intrassilábicas, a tendência é de fato uma busca por estruturas relativamente menos marcadas que as originais. Além disso, vai ao encontro daquilo que sugere Abaurre (2001), isto é, de que fenômenos como a metátese "representam casos em que as crianças parecem não conseguir resolver, na escrita, o problema da correta representação dos segmentos que ocupam posições em sílabas com estrutura mais complexa do que CV"' (Abaurre, 2001, p. 68).

\subsubsection{Metáteses intersilábicas}

Tendo em vista os resultados referentes à metátese intrassilábica nos dados de escrita, recém apresentados, pode-se perguntar se o mesmo seria verificável em se considerando a metátese intersilábica, cuja característica é a mobilidade de um segmento que transpassa a sílaba de origem.

$\mathrm{Na}$ tabela 5 estão os resultados relativos às metáteses intersilábicas com ênfase na qualidade das estruturas silábicas originais (sílaba-gatilho) e no resultado da ocorrência da metátese na estrutura resultante (sílaba-alvo), a fim de que se possa comparar a modificação gerada na estrutura da sílaba-gatilho, portadora do segmento que é deslocado, e a estrutura da sílaba-alvo, aquela que recebe o segmento deslocado e que é efetivamente grafada pelas crianças. 
Tabela 5 - Distribuição dos dados de metáteses intersilábicas comparando a modificação gerada na sílaba-gatilho com a modificação gerada na sílaba-alvo, a partir do deslocamento do segmento de uma sílaba à outra.

\begin{tabular}{|c|c|c|c|c|}
\hline \multirow{2}{*}{$\begin{array}{c}\text { Estrutura } \\
\text { da silaba-gatilho }\end{array}$} & \multirow{2}{*}{$\begin{array}{c}\text { Estrutura } \\
\text { da sílaba-alvo }\end{array}$} & \multicolumn{2}{|c|}{ Frequência de ocorrência } & \multirow{2}{*}{ Exemplo } \\
\hline & & $N^{o_{s}} \cdot$ absolutos & Percentual & \\
\hline \multirow{4}{*}{$\mathrm{CVC} \rightarrow \mathrm{CV}$} & $\mathrm{V} \rightarrow V C$ & 4 & $13,3 \%$ & enorme $\rightarrow$ ernome \\
\hline & $\mathrm{CV} \rightarrow \mathrm{CCV}$ & 3 & $10 \%$ & corda $\rightarrow$ codra \\
\hline & $\mathrm{CV} \rightarrow C V C$ & 3 & $10 \%$ & floresta $\rightarrow$ floletas \\
\hline & $\mathrm{CVC} \rightarrow \mathrm{CCVC}$ & 3 & $10 \%$ & pintar $\rightarrow$ printa \\
\hline \multirow{2}{*}{$C C V \rightarrow C V$} & $\mathrm{CV} \rightarrow \mathrm{CCV}$ & 5 & $16,7 \%$ & quebra $\rightarrow$ creba \\
\hline & $\varnothing \rightarrow C V$ & 2 & $6,7 \%$ & zebra $\rightarrow$ zereba \\
\hline \multirow{3}{*}{$\mathrm{CCVC} \rightarrow \mathrm{CV}(\mathrm{C})$} & $\mathrm{CVC} \rightarrow \mathrm{CCV}$ & 3 & $10 \%$ & tão grandes $\rightarrow$ trãgades \\
\hline & $\mathrm{CV} \rightarrow C V C$ & 2 & $6,7 \%$ & triste $\rightarrow$ tritis \\
\hline & $\mathrm{CVC} \rightarrow \mathrm{CCVC}$ & 1 & $3,3 \%$ & padrastos $\rightarrow$ padastros \\
\hline $\mathrm{CCVCC} \rightarrow \mathrm{CCVC}$ & $\mathrm{V} \rightarrow V C$ & 1 & $3,3 \%$ & $\begin{array}{l}\text { e transformar } \rightarrow \\
\text { estram for mar }\end{array}$ \\
\hline$V C C \rightarrow \mathrm{V}$ & $\mathrm{CV} \rightarrow C V C$ & 1 & $3,3 \%$ & inspetor $\rightarrow$ ipestor \\
\hline $\mathrm{CVCC} \rightarrow \mathrm{CVC}$ & $\mathrm{CV} \rightarrow \mathrm{CVC}$ & 1 & $3,3 \%$ & patins $\rightarrow$ pantis \\
\hline Tota & & 30 & $100,00 \%$ & \\
\hline
\end{tabular}

Os resultados na tabela 5 reforçam uma tendência já observada para as metáteses intrassilábicas (ver tabela 3): as sílabas-gatilho, portadoras dos segmentos deslocados, ou seja, aquelas que parecem provocar a ocorrência do fenômeno, são, em algum nível, todas complexas, uma vez que têm em sua estrutura onset e/ou rima ramificados. Isso indica que os contextos favorecedores da metátese (independente se inter ou intrassilábica) parecem ser aqueles que apresentam estruturas silábicas complexas, além de sugerir uma preferência da língua por formas canônicas.

Ademais, os dados apresentados na tabela mostram que a ocorrência da metátese gera um esvaziamento de constituintes na sílaba-gatilho, simplificando sua estrutura, e, ao mesmo tempo, aumentando o grau de complexidade das sílabas-alvo, como mostram os exemplos em itálico e em negrito na tabela 5 e como pode ser observado na representação na figura 3: 


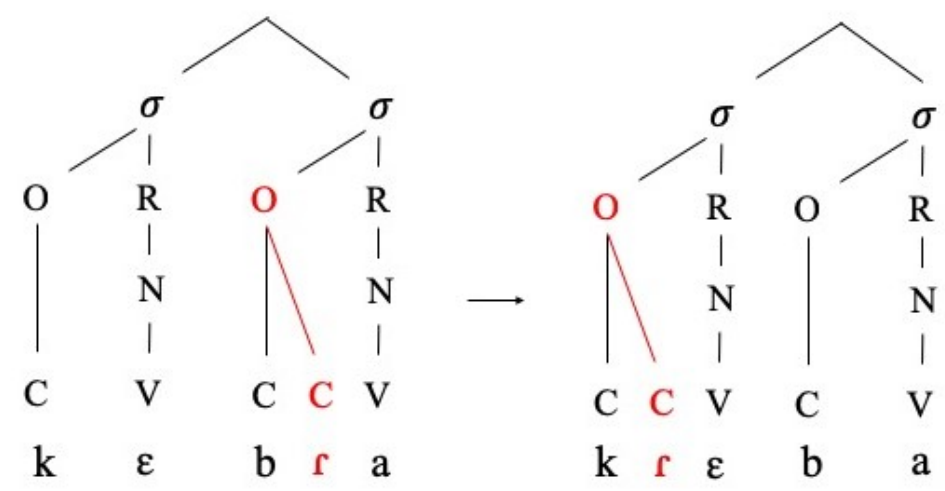

Fonte: Elaboração das autoras.

Figura 3 - Representação da metátese intersilábica 'creba' para 'quebra', com base no modelo autossegmental de Selkirk (1982).

Interessante é notar que esse processo de preenchimento é feito, majoritariamente, preservando a característica original da sílaba-gatilho, isto é, conservando sua estrutura sobretudo no que diz respeito à presença de onset ou rima ramificados, como no exemplo em 'creba' para 'quebra'. A tabela 6 ilustra a distribuição deste tipo de comportamento nos dados analisados:

Tabela 6 - Distribuição dos dados de escrita conforme tipo de resultado das metáteses intersilábicas em termos de complexidade da estrutura silábica (perda, manutenção ou aumento de complexidade).

\begin{tabular}{cccc}
$\begin{array}{c}\text { Tipo de processo } \\
\text { (complexidade silábica) }\end{array}$ & $\begin{array}{c}\text { Frequência de ocorrência } \\
\text { N. }{ }^{\text {s }} \text { absolutos }\end{array}$ Percentual & Exemplo \\
\hline $\begin{array}{c}\text { Manutenção de } \\
\text { complexidade }\end{array}$ & 21 & $70 \%$ & trabalha $\rightarrow$ tabralha \\
$\begin{array}{c}\text { Perda de complexidade } \\
\text { Aumento de complexidade }\end{array}$ & 5 & $16,7 \%$ & frio $\rightarrow$ firo \\
\hline Total & 4 & $13,3 \%$ & alargou $\rightarrow$ alacro \\
\hline
\end{tabular}

Os dados da tabela 6 ilustram o que foi recém mencionado: os casos de metátese intersilábica, de forma preponderante, procuram preservar a estruturagatilho, posicionando o segmento em outra sílaba da palavra no constituinte adequado (como no exemplo dado, 'tabralha' para 'trabalha', no qual a segunda posição do onset complexo é conservada). Interpretamos esse comportamento como um indício de uma sensibilidade das crianças a respeito da configuração estrutural das sílabas, no nível representacional. Assim, a grafia realizada parece estar associada mais a uma incerteza sobre qual das silabas deve portar o segmento, considerando-se que ambas as oclusivas da palavra poderiam compor um onset complexo com a líquida não-lateral, e menos a uma incerteza sobre onde posicionar determinado segmento na estrutura interna das sílabas. 
Com isso, é possível finalmente responder a questão que iniciou esta seção: o resultado da metátese intersilábica seria semelhante àquele encontrado para as metáteses intrassilábicas, no que se refere a processos de perda ou aumento de complexidade silábica?

A resposta depende do critério adotado. Isto é, se for observada a modificação gerada na sílaba-gatilho e na sílaba-alvo de forma isolada, a conclusão será ambígua: existe, por um lado, um processo de simplificação da estrutura da sílaba-gatilho, em virtude de um esvaziamento segmental ocasionado pela metátese; por outro, existe um processo de aumento de complexidade da estrutura da sílaba-alvo, uma vez que há um preenchimento segmental também ocasionado pela metátese. Nesse sentido, portanto, o resultado da metátese intersilábica seria, em parte, semelhante àquele verificado nas metáteses intrassilábicas.

Porém, se for comparada a modificação gerada na sílaba-alvo, a partir do preenchimento segmental, com a estrutura original da sílaba-gatilho, o desfecho será apenas um: ocorre preferencialmente um processo de manutenção da estrutura da sílabagatilho, de forma a preservar características silábicas importantes como ordem e posicionamento dos segmentos. Assim, o resultado da metátese intersilábica seria claramente distinto daquele verificado para as metáteses intrassilábicas, evidenciando que os dois grupos diferem, na escrita, não somente em termos quantitativos mas também qualitativamente.

\subsubsection{Variáveis secundárias}

Embora a metátese segmental simples, tanto intra quanto intersilábica, mostrese fortemente ligada a aspectos de complexidade silábica, no sentido de tentar solucionar a correta representação dos segmentos em posições de sílaba ramificadas, seria possível verificar a incidência de variáveis de natureza distinta, ainda que tenham importância secundária? Esse aspecto as subseções que seguem procuram contemplar.

\subsubsection{Segmentação gráfica e nasalidade}

Ao revisitar o grupo das metáteses segmentais simples, uma outra característica interessante para a discussão proposta pode ser observada: nele estão palavras que apresentam uma espécie de "concentração de desafios representacionais" às crianças, que se estendem para além da complexidade silábica, tais como a segmentação gráfica e a nasalidade.

Em um dado como 'espedeu' para 'se perdeu', produzido por um aluno de $2^{a}$ série, a metátese ocorre em meio a um típico caso de hipossegmentação ${ }^{13}$ envolvendo

\footnotetext{
12 Por esta expressão fazemos referência aos diferentes níveis de complexidade que determinadas sequências gráficas podem apresentar ao aprendiz. Tal complexidade pode ser definida pelo grau de opacidade, isto é, pelas assimetrias existentes entre o plano fonológico e o plano gráfico de determinada sequência.

13 A hipossegmentação, caracterizada pela não-observação dos espaços em branco entre as palavras, é um dos mais frequentes tipos de erro ortográfico nos primeiros anos da escolarização (Cunha, 2004; Miranda, 2013). No Brasil, Abaurre (1991b) é pioneira na abordagem fonológica das segmentações nãoconvencionais em dados de aquisição da escrita. Estudos mais recentes têm produzido análises das hipo e hipersegmentações em dados de alunos do Ensino Fundamental I (Cunha, 2004; Chacon, 2004; Capristano, 2004) e do Ensino Fundamental II (Tenani, 2004).
} 
um grupo clítico, de modo que o segmento deslocado parece atuar como elemento de juntura entre o clítico e a palavra fonológica.

A ideia é a de que a metátese pode emergir como uma estratégia auxiliar na resolução de uma demanda que, no momento, é prioritária para a criança, não necessariamente ligada à estrutura silábica, uma vez que a estrutura da sílaba-gatilho, no caso, é CV, bastante simples em termos de representação fonológica e gráfica. Assim, a prioridade parece ser oferecer uma solução para a segmentação das palavras.

Em 'esvitiu' para 'se vestiu', grafia produzida por aluna de $1^{a}$ série, o raciocínio é o mesmo, embora se observe a preservação da ramificação da estrutura-gatilho na estrutura-alvo ( $\mathrm{CVC} \rightarrow \mathrm{VC}$ ), ou seja, a criança procura resolver simultaneamente o desafio da segmentação e da adequada representação da complexidade silábica. Ainda assim, a metátese parece continuar à serviço da tarefa de segmentação, visto que o segmento deslocado ocupa justamente o espaço entre o clítico e a palavra fonológica.

Esse é um aspecto que difere qualitativamente a ocorrência da metátese na aquisição da escrita em relação à aquisição da fala ou mesmo à fala adulta, uma vez que, nesta modalidade da língua, a segmentação de palavras não é um desafio cognitivo a ser conscientemente resolvido, pois faz parte do processo de aquisição espontânea da língua.

Outro aspecto que deve ser observado é a presença de nasalidade medial. A referência à nasalidade aqui é feita especificamente a um grupo de metáteses (26 ocorrências no total) no qual se verifica a presença de uma consoante nasal pósvocálica dentro da palavra onde ocorre o fenômeno. No entanto, a metátese nesses casos não é observada atuando necessariamente sobre a consoante nasal, mas sim, de forma majoritária, sobre outros segmentos dentro da palavra. A questão aqui, portanto, é pensar na possibilidade de que a nasalidade possa contribuir como gatilho para a ocorrência da metátese de segmentos vizinhos. Exemplos desse tipo de dado são 'gerde' para 'grande' ( $1^{a}$ série) e 'palntando' para 'plantando' ( $3^{\mathrm{a}}$ série).

Para compreender a relevância desta variável, é necessário evocar os expressivos estudos e discussões feitos em torno da nasalidade na escrita, dentre os quais destacam-se os de Abaurre (1988), Miranda (2009, 2012, 2018) e Miranda e Cunha (ano), cujas contribuições estão, especialmente, em apontar a existência de uma incerteza notável por parte das crianças no que tange à grafia da nasal pós-vocálica em posição medial, o que pode remeter a questões relacionadas ao caráter representacional da nasalidade no sistema do português, isto é, se seria mono ou bifonêmica.

No primeiro exemplo mencionado, 'gerde', o dado faz referência a um item lexical específico que dentro do BATALE (Miranda, 2001) apresenta mais de 10 possibilidades de grafia: a palavra 'grande' (Miranda, 2009). É importante notar que, nessa palavra, a complexidade parece derivar de aspectos tipicamente fonológicos, uma vez que ortograficamente a palavra é simples, "sem casos importantes de relação múltipla, que é o tipo de relação que oferece mais problemas ao aprendiz" (Miranda, 2009, p. 420; cf. Lemle, 1987, para relações fonema/grafema na escrita). Ao que se deve atentar, portanto, é à estrutura fonológica, constituída de uma sílaba com consoante nasal na posição de coda, além do onset complexo, do que decorre a formação da estrutura silábica supercomplexa CCVC. Segundo Miranda (2009), a tentativa de resolução a respeito da forma gráfica mais adequada à representação da supercomplexidade pode ser a causa das diferentes estratégias utilizadas pelas crianças, 
nas quais está inclusa a metátese como opção, o que auxilia a sustentar a ideia da complexidade do registro da nasalidade como gatilho para a metátese.

O segundo exemplo, 'palntando', ilustra um grupo característico de casos cujo resultado da metátese termina por ferir restrições tanto fono quanto grafotáticas ${ }^{14}$. A nasalidade parece atuar como aspecto relevante nesse conjunto, em virtude de serem apenas os dados que apresentam tal característica na sua constituição aqueles que, dentro de toda amostra analisada, ferem as mencionadas restrições, com exceção de somente dois itens que não possuem consoante nasal no seu contexto ('fazre' para 'fazer' e 'vremelo' para 'vermelho'). Assim, é possível interpretar que, neste conjunto de dados, a metátese pode estar sendo motivada pela (super)complexidade local, sobretudo pela rima ramificada preenchida pela consoante nasal.

Tal como assinalado nos casos de segmentação gráfica, os dados envolvendo a nasalidade medial são bastante importantes no sentido de apontar para mais uma assimetria nas relações entre fala e escrita. Primeiro, porque a nasalidade não é apontada como um fator contributivo para a ocorrência da metátese na aquisição da fala e na fala adulta. Além disso, as formas derivadas das metáteses como ilustradas pelo dado 'palntando' são impossíveis de ocorrência na fala, justamente porque ferem restrições fonotáticas da língua.

Assim, a conclusão desta subseção pode ser sintetizada da seguinte maneira: nas metáteses segmentais simples, existe um grupo considerável de dados que indicam influências de outra natureza, que não necessariamente incluem a complexidade silábica, para atrair a atenção da criança no momento da escrita, fazendo com que seja secundário, por vezes, o desafio de posicionar e ordenar corretamente os segmentos nos constituintes silábicos. Este fato indica uma assimetria importante entre a metátese verificada na escrita e na fala.

\subsubsection{Pé métrico}

O pé métrico, unidade prosódica definida pela Fonologia Métrica (Halle; Vergnaud, 1987; Hayes, 1995) como a associação de duas ou mais sílabas entre as quais se fixa uma relação de dominância, é tomado como variável relevante para análise da metátese na aquisição fonológica por Lamprecht (2002) e Redmer $(2007)^{15}$. Seria esta uma variável também pertinente para abordar os dados de escrita?

Na tabela 7, os dados de escrita estão distribuídos considerando a ocorrência da metátese segmental simples em relação à presença do pé troqueu, desconsiderando, no entanto, se os segmentos se deslocam na ou em direção à sílaba portadora do acento primário na palavra:

\footnotetext{
${ }^{14}$ A grafotática é o estudo das sequências de grafemas licenciadas por um determinado sistema de escrita.

${ }^{15}$ É imprescindível referir aqui o estudo de Magalhães (2003), que procura identificar o sistema de pé que as crianças adquirem durante o desenvolvimento fonológico por meio da análise de dados de metátese envolvendo a líquida não-lateral /r/. Como seu foco não é a metátese propriamente dita, mas sim o pé troqueu, optou-se por discutir os dados de escrita fazendo referência direta apenas ao estudo de Lamprecht (2002) e Redmer (2007).
} 
Tabela 7 - Distribuição dos dados considerando a ocorrência da metátese segmental simples em relação à presença do pé troqueu portador do acento primário.

\begin{tabular}{|c|c|c|c|}
\hline Tipo de processo (pé métrico) & $\begin{array}{l}\text { Frequência } \\
N \text {. }^{o_{s}} \text { absolutos }\end{array}$ & $\begin{array}{l}\text { e ocorrência } \\
\text { Percentual }\end{array}$ & Exemplo \\
\hline Dentro do pé do acento & 60 & $58,8 \%$ & lu.gar $\rightarrow$ lu.gra \\
\hline $\begin{array}{c}\text { Em direção ao pé do } \\
\text { acento }\end{array}$ & 2 & $2 \%$ & a.lar.gou $\rightarrow$ a.la.cro \\
\hline Fora do pé do acento & 35 & $34,3 \%$ & a.cro.ba.ci.a $\rightarrow$ a.co.bra.si.a \\
\hline $\begin{array}{c}\text { Para fora do pé do } \\
\text { acento }\end{array}$ & 5 & $4,9 \%$ & pin.tar $\rightarrow$ prin.ta \\
\hline Total & 102 & $100 \%$ & \\
\hline
\end{tabular}

Os resultados apresentados na tabela mostram que há uma tendência de as metáteses ocorrerem dentro do pé do acento primário (58,8\% de ocorrências) ou, em raros casos, direcionarem o segmento deslocado ao pé, caso estejam fora $(2 \%$ de ocorrências). A soma dos percentuais nesses casos totaliza $61 \%$, um valor que permite considerar a tendência de a metátese segmental simples ocorrer com mais frequência quando os segmentos ocupam o pé portador do acento primário da palavra, o que se alinha aos resultados de Redmer (2007).

Redmer (2007), no entanto, analisa esta variável de forma mais específica, observando que toda vez que a metátese gera estruturas mais complexas que as originais, a sílaba gerada está em posição proeminente na palavra fonológica, ou seja, no pé portador do acento primário, como em ['vredzi], por exemplo.

Lamprecht (2002) também realiza um exercício de análise mais pontual, observando qual sílaba do pé troqueu (forte ou fraca) porta ou recebe o segmento deslocado. A autora chega à conclusão de que a sílaba acentuada do pé métrico funciona como unidade atratora da consoante deslocada no processo de metátese, especialmente nos casos das intersilábicas.

No conjunto de dados de escrita analisados, não foram verificadas regularidades tais como a observadas por Lamprecht (2002) e Redmer (2007), isto é, de as metáteses intersilábicas (em casos de aumento de complexidade, para Redmer), buscarem preferencialmente a borda esquerda do pé trocaico.

Assim, do ponto de vista mais amplo, como aquele apresentado pela tabela 7, constata-se uma simetria entre a ocorrência da metátese na aquisição da fala e da escrita, no que se refere à presença do pé métrico como contexto favorecedor do processo. Entretanto, do ponto de vista mais estrito, ao se levar em consideração fatores como direção do movimento e sílaba proeminente, especificamente em relação a metáteses intersilábicas, o resultado é diferente nas duas modalidades da língua.

\subsection{Metáteses segmentais duplas}

Até este ponto do texto, foram amplamente exploradas as metáteses segmentais simples, considerando seus efeitos e particularidades. A partir desta 
subseção, o foco incide sobre as metáteses segmentais duplas, que apresentam uma característica bastante distinta das simples: elas não resultam em alteração da estrutura silábica, visto que envolvem dois segmentos cuja posição na sílaba é sempre a primeira em um onset simples $(\mathrm{CV} \rightarrow \mathrm{CV})$. A metátese transcorrida nesse contexto consiste, assim, na inversão mútua das posições desses segmentos dentro da palavra, como em 'tolenadas' para 'toneladas'.

Tendo em vista sua caracterização, este grupo de metáteses demanda, para a sua análise, a consideração de outro tipo de variável que não a estrutura silábica. Para Redmer (2007), é a estrutura dos segmentos, especificamente no tocante a traços de ponto (Clements; Hume, 1995), que pode fornecer uma alternativa explicativa para as metáteses segmentais duplas. O que a pesquisadora observa é que em todos os contextos onde atua esse tipo de metátese, há pelo menos uma consoante [coronal] e há tendência à transposição, do segmento portador do traço [coronal], para a posição de onsets à esquerda (Redmer, 2007). Seria possível atestar algo semelhante nos dados de escrita?

Para responder a pergunta, os dados foram organizados a partir do critério traços de ponto, considerando a caracterização proposta na Teoria Autossegmental (Clements; Hume, 1995). Por essa perspectiva, existe uma camada na estrutura interna dos segmentos caracterizada pelo ponto de articulação das consoantes (nó Pontos de C), que pode ser economicamente formalizada em três traços principais, os quais atestadamente atuam de forma solidária em diversos processos nas línguas em geral: [labial], [coronal] e [dorsal]. A partir deles, foram gerados alguns agrupamentos nos dados da amostra, os quais podem ser observados na tabela 8:

Tabela 8 - Distribuição das metáteses segmentais duplas a partir dos traços de ponto portados pelos segmentos envolvidos.

\begin{tabular}{|c|c|c|c|}
\hline $\begin{array}{l}\text { Traços de ponto } \\
\text { dos segmentos }\end{array}$ & Erro & Palavra Alvo & $\begin{array}{l}\text { Frequência de } \\
\text { ocorrência } \\
\text { (n.os absolutos) }\end{array}$ \\
\hline labial e coronal & $\begin{array}{ll}\text { 1. } & \text { mun } \\
\text { 2. } & \text { nomte } \\
\text { 3. } & \text { aminal } \\
\text { 4. } & \text { mornal } \\
\text { 5. } & \text { mornau } \\
\text { 6. } & \text { ele tefinho } \\
\text { 7. } & \text { bolo }(4 x)\end{array}$ & $\begin{array}{c}\text { num } \\
\text { monte } \\
\text { animal } \\
\text { normal } \\
\text { normal } \\
\text { elefantinho } \\
\text { lobo }\end{array}$ & 10 \\
\hline coronal e coronal & $\begin{array}{l}\text { 8. } \text { tende } \\
\text { 9. } \text { tolenadas } \\
\text { 10. } \text { plo brel ma }\end{array}$ & $\begin{array}{l}\text { dente } \\
\text { toneladas } \\
\text { problema }\end{array}$ & 3 \\
\hline labial e labial & 11. porvafor & por favor & 1 \\
\hline
\end{tabular}


Os dados apresentados na tabela 8 evidenciam uma tendência à presença dos traços [labial] e [coronal] e uma aparente rejeição à transposição de segmentos portadores do traço [dorsal], uma vez que não há sequer um dado que registre a presença desse traço. À semelhança de Redmer (2007), é possível observar, assim, a presença praticamente categórica de segmentos coronais nas metáteses segmentais duplas. Por outro lado, não é possível afirmar uma tendência à transposição desses segmentos em direção à borda esquerda, visto que segmentos labiais e coronais se alternam equitativamente no que diz respeito à direção do movimento.

Com relação aos subgrupos [coronal] e [coronal] e [labial] e [labial], nos quais as consoantes envolvidas compartilham traços de ponto, é plausível supor que haja uma motivação para a ocorrência da metátese advinda da natureza segmental ao ser considerado o fato de que se trata de pares de consoantes distintas apenas pelo traço [sonoro] e que atuam associadamente em outros processos fonológicos nas línguas em geral (cf. Matzenauer, 2005).

Contudo, é o grupo que se destaca numericamente em relação aos demais, formado pelas consoantes labiais e coronais, que oportuniza maiores discussões. Dentro dele, é possível realizar ainda alguns outros subagrupamentos.

Dos itens 1 a 5 destacam-se as metáteses envolvendo consoantes nasais. Essa subdivisão pode ser elucidativa no seguinte sentido: $/ \mathrm{m} / \mathrm{e} / \mathrm{n} /$ são fonemas representados por pares de grafemas muito semelhantes em termos de traçado ('m'/'M' e 'n'/'N', respectivamente), propriedade importante constitutiva dos sistemas notacionais (Landsmann, 1995) e potencialmente confundidas pelas crianças em um período inicial de aquisição da escrita (Miranda, 2018), o que implicaria na possibilidade de que esse tipo de erro talvez esteja muito mais vinculado a aspectos notacionais do que fonológicos propriamente ditos. Essa hipótese vai ao encontro daquilo que aponta Miranda (2018), em estudo sobre a grafia da nasalidade na escrita inicial. A pesquisadora encontra um percentual de $15 \%$ de erros envolvendo a grafia de consoantes nasais em posição de ataque (como 'sobrenesa' para 'sobremesa'), aos quais atribui, como motivação, traçado de letra. Segundo ela, o sujeito que está aprendendo a escrever

\footnotetext{
tem de lidar com diferentes fontes de informação, sejam derivadas do universo gráfico (nomes de letras, tipos de letras, formas das letras, sequências de letras etc) sejam oriundas do seu conhecimento linguístico internalizado (Miranda, 2018, p. 19).
}

Já com relação ao segundo subgrupo, formado pelos itens lexicais "elefantinho" e "lobo", é plausível pensar que algum aspecto de natureza segmental pode efetivamente estar atuando como gatilho para o fenômeno, se for considerado que há uma preferência geral para a ocupação da borda esquerda da palavra por determinados tipos de segmentos, a saber [-soante, -contínuo] (Miranda, 2005). Tal condição /t/ e /b/ satisfazem melhor que /f/ e /l/, ao observarmos os pares de consoantes envolvidas nas metáteses dos itens lexicais indicados. Nesse sentido, é interessante notar que para a grafia de 'ele tefinho' para 'elefantinho', além da metátese é realizada uma hipersegmentação, isto é, a inserção de um espaço em branco em lugar não previsto pela norma ortográfica, criando, por assim dizer, uma borda esquerda absoluta, para onde /t/, a consoante [-soante, -contínua], se desloca. 
Essa observação, ao mesmo tempo que corrobora a possibilidade explicativa advinda da teoria fonológica, também auxilia a pensar mais uma vez sobre a particularidade do dado de escrita em relação ao dado de fala. Tipicamente, a hipersegmentação é uma variedade de erro que aparece mais tardiamente na escrita de crianças em período de aquisição da escrita, visto que parece depender de sua inserção em práticas escolares de leitura e escrita, a partir das quais começa a se distanciar da percepção da fala como cadeia contínua, a reconhecer palavras gramaticais e a identificar sílabas como elementos funcionais (Cunha, 2010). Assim, trata-se de um recurso não motivado fonologicamente e que, portanto, jamais ocorreria espontaneamente na fala, seja adulta ou infantil. Entretanto, no caso analisado em 'ele tefinho' para 'elefantinho', a hipersegmentação parece se inserir de modo estratégico, de modo que licencia, ou ao menos facilita, a ocorrência da metátese, pois produz um contexto fonológico mais favorável à ordem de fonemas resultante $(/ \mathrm{t} /$ seguido de $/ \mathrm{f} /$ ) que a de origem (/f/ seguido de /t/). Dessa maneira, observam-se as sutis assimetrias e simetrias entre fala e escrita, bem como o jogo de permutas e entrelaçamento que realizam entre si a fim de possibilitar uma escolha gráfica, o que ajuda a distinguir os dois sistemas. Coelho (2016) também indica essa característica como constitutiva das relações entre fala e escrita, salientando que elas não são necessariamente "de espelhamento" e que "aquisição da escrita, embora fortemente ancorada, sobretudo em seu início, em características da fala, não se reduz esse tipo de ancoragem" (Coelho, 2016, p. 80).

\section{CONSIDERAÇÕES FINAIS}

Este artigo teve por objetivo explorar, em diálogo com estudos fonológicos, a grafia da metátese encontrada em textos produzidos por crianças no período de aquisição da escrita. Os resultados apresentados trazem contribuições para a discussão do fenômeno em foco, bem como ressaltam aspectos de convergência entre as escritas iniciais e o conhecimento fonológico das crianças, sem descuidar daquilo que diz respeito especificamente ao sistema de escrita.

O estudo aborda dois tipos de metátese encontrados na escrita, os quais apresentam características e comportamentos distintos entre si: as metáteses segmentais simples e as segmentais duplas, em paralelo ao que é verificado na aquisição da fala.

Os dados analisados mostram que, do ponto de vista fonológico, traços de ponto, estrutura silábica e nasalidade medial apresentam-se como variáveis relevantes para a ocorrência da metátese, combinando-se e alternando-se em grau de influência a depender do tipo de metátese (simples ou duplas) e do contexto fonológico do item lexical atingido. Dessa maneira, é reforçada a influência de determinados aspectos já salientados por outros pesquisadores com relação à metátese, como a natureza dos segmentos envolvidos (Hume, 2001, 2004; Redmer, 2007), a estrutura silábica e seu grau de complexidade (Zitzke, 1998, 2001; Redmer, 2007; Lamprecht, 2002; Coelho, 2016) e a incerteza representacional ligada à grafia da nasalidade em coda medial (Abaurre, 1988; Miranda, 2009, 2012, 2018; Miranda; Cunha, 2013) e à segmentação gráfica em casos de hipossegmentação (Abaurre, 1991b; Miranda; Cunha, 2013; Tenani, 2012). 
Algumas assimetrias foram observadas entre o processo de metátese na fala e na escrita, ressaltando a especificidade de cada modalidade da língua e a interferência de fatores externos à fonologia, como traçado de letra e segmentação gráfica (em casos de hipersegmentação), variáveis que dizem respeito a conhecimentos notacionais, também constitutivos da aprendizagem do sistema de escrita e que interagem com aquelas de natureza fonológica.

Assim, com os dados apresentados, procura-se contribuir não apenas para a descrição do fenômeno analisado, que conta com poucas pesquisas relativamente à sua ocorrência na aquisição da escrita, mas também para evidenciar o seu caráter complexo e multifacetado, bem como os cuidados teórico-metodológicos que exige em sua análise. Com isso, também deseja-se contribuir para o fortalecimento da ideia de uma complexa relação, nem sempre simétrica, entre fonologia e ortografia.

\section{REFERÊNCIAS}

Abaurre MBM. The interplay between spontaneous writing and underlying linguistic representation. European Journal of Psychology Education. 1988;40(3)415-430.

Abaurre MBM. Os estudos linguísticos e a aquisição da escrita. II Encontro sobre Aquisição de Linguagem; 1991a; Porto Alegre, Brasil.

Abaurre MBM. A relevância dos critérios prosódicos e semânticos na elaboração de hipóteses sobre segmentação na escrita inicial. Boletim da ABRALIN. 1991b;11:203-217.

Abaurre MBM. Dados da escrita inicial: indícios da construção da hierarquia de constituintes silábicos? In: Matzenauer CLB, organizador. Aquisição de língua materna e de língua estrangeira. Pelotas: EDUCAT; 2001. p. 63-86.

Adamoli MA. Um estudo sobre o estatuto fonológico dos ditongos variáveis [aj] e [ei] do PB a partir de dados orais e ortográficos produzidos por crianças de séries iniciais [tese]. Pelotas: Faculdade de Educação, Universidade Federal de Pelotas; 2012.

Blevins J, Garret A. The evolution of metathesis. In: Hayes B, Kirschner R, Steriade D, editores. Phonetically based phonology. Cambridge: Cambridge University Press; 2004.

Capristano CC. A propósito da escrita infantil: uma reflexão sobre as segmentações nãoconvencionais. Letras de Hoje. 2004;39(3):245-260.

Chacon L. Constituintes prosódicos e letramento em segmentações não-convencionais. Letras de Hoje. 2004;39(3):223-232.

Chomsky N. Aspectos da teoria da sintaxe. 2a ed. Coimbra: Editor-Sucessor; [1965] 1978.

Clements NG, Hume E. The internal organization of speech sounds. In: Goldsmith, JA, editor. The handbook of phonological theory. Cambridge: Blackwell Publishers; 1995.

Coelho BC. Transposições ortográficas e estrutura da sílaba na escrita infantil [dissertação]. São José do Rio Preto: Instituto de Biociências, Letras e Ciências Exatas, Universidade Estadual Paulista Júlio de Mesquita Filho; 2016.

Cunha APN. A hipo e a hipersegmentação nos dados de aquisição da escrita: um estudo sobre a influência da prosódia [dissertação]. Pelotas: Faculdade de Educação, Universidade Federal de Pelotas; 2004.

Cunha APN. As segmentações não-convencionais da escrita inicial: uma discussão sobre o ritmo linguístico do português brasileiro e europeu [tese]. Pelotas: Faculdade de Educação, Universidade Federal de Pelotas; 2010.

Ferreiro E, Teberosky A. Psicogênese da língua escrita. Porto Alegre: ArtMed; 1999.

Halle M, Vergnaud JR. An essay on stress. Cambridge: MIT Press; 1987. 
Hayes B. Metrical stress theory: principles and case studies. Chicago: University of Chicago Press; 1995.

Hora D, Telles S, Monaretto VNO. Português brasileiro: uma língua de metátese?. Letras de Hoje. 2007;42 (2):178-196.

Hume E. Metathesis: formal and functional considerations. In: Hume E, Smith N, Weijer J van de, editores. Surface syllable structure and segment sequencing. Leiden: HIL; 2001. p. 1-25.

Hume E. The indeterminacy/attestation model of metathesis. Language. 2004;80(2):203-237.

Lamprecht RR. Metathesis in phonological acquisition: a window to constraint ranking in the child's system. GALA-Generative Approaches to Language Acquisition; 2002; Palmela, Portugal.

Lamprecht RR et al., organizadores. Aquisição fonológica do português: perfil de desenvolvimento e subsídios para terapia. Porto Alegre: ArtMed; 2004.

Landsmann LT. Aprendizagem da linguagem escrita: processos evolutivos e implicações didáticas. São Paulo: Ática; 1995.

Lemle M. Guia teórico do alfabetizador. São Paulo: Ática; 1987.

Magalhães JS. A metátese da líquida não-lateral na aquisição: evidência para o pé troqueu. Letras de Hoje. 2003;38(2): 83-95.

Matzenauer CLB. Introdução à teoria fonológica. In: Bisol L, organizador. Introdução a estudos de fonologia do português brasileiro. $4^{\mathrm{a}}$ ed. rev. e ampl. Porto Alegre: EDIPUCRS, [1996] 2005.

Matzenauer-Hernandorena CLB. Aquisição da fonologia do português: estabelecimento de padrões com base em traços distintivos [tese]. Porto Alegre: Instituto de Letras e Artes, Pontifícia Universidade Católica de Porto Alegre; 1990.

Matzenauer-Hernandorena CLB. A aquisição de segmentos do português e o pé métrico. Letras de Hoje. 2001;36(3):85-99.

McCarthy J, Prince AS. Prosodic morphology I: constraint interaction and satisfaction. New Brunswick: Rutgers University Center for Cognitive Science; 1993.

Miranda ARM. A aquisição do 'r': uma contribuição à discussão sobre seu status fonológico [dissertação]. Porto Alegre: Instituto de Letras e Artes, Pontifícia Universidade Católica de Porto Alegre; 1996.

Miranda ARM. BATALE: Banco de textos de aquisição da linguagem escrita [internet]. Pelotas: Faculdade de Educação, Universidade Federal de Pelotas; 2001. Disponível em: https://sistemavestigios.org.

Miranda ARM. As formas harmônicas da linguagem infantil e a atuação das restrições [SPREAD] e [AGREE]. In: Cadernos de pesquisa em Linguística. 2005;1(1).

Miranda ARM. A grafia de estruturas silábicas complexas na escrita de crianças das séries iniciais. In: Pinho SZ, organizador. Formação de Educadores: o papel do educador e sua formação. São Paulo: Unesp; 2009. p. 409-426.

Miranda ARM. Reflexões sobre a fonologia e a aquisição da linguagem oral e escrita. Veredas online. 2012;16:118-135.

Miranda ARM. Informação fonológica na aquisição da escrita. In: Ré, A, Komesu F, Tenani L, Vieira AJ, organizadores. Estudos linguísticos contemporâneos: diferentes olhares. São Paulo: Cultura Acadêmica; 2013. p. 11-35.

Miranda ARM. A fonologia em dados de escrita inicial de crianças brasileiras. Linguistica (Madrid). 2014;30:45-80.

Miranda ARM. Aquisição da escrita: as pesquisas do GEALE. In: Miranda ARM, Cunha APN, Donicht G, organizadores. Estudos sobre Aquisição da Linguagem Escrita. Pelotas: Editora UFPel; 2017. p. $15-50$. 
Miranda ARM. Aquisição da linguagem: escrita e fonologia. In: Lazzarotto-Volcão C, Freitas MJ, organizadores. Estudos em Fonética e Fonologia: coletânea em homenagem a Carmen Matzenauer. Curitiba: CRV; 2018. p. 335-364.

Miranda ARM, Cunha APN. Indícios de reestruturação do conhecimento fonológico da criança em dados de reparo na escrita inicial. Letras de Hoje. 2013;48(3):343-354.

Miranda ARM, Silva MR, Medina SZ. O sistema ortográfico do português brasileiro e sua aquisição. Revista Linguagens e Cidadania. 2005;14(1):1-15.

Ney LAG. Acentuação gráfica na escrita de crianças de séries iniciais [dissertação]. Pelotas: Faculdade de Educação, Universidade Federal de Pelotas; 2012.

Pachalski L, Rodrigues JC, Vieira IF, Miranda ARM. A produção de encontros consonantais tautossilábicos em dados de escrita inicial. XXIII Congresso de Iniciação Científica da UFPel; 2014; Pelotas, RS, Brasil. Disponível em: http://cti.ufpel.edu.br/siepe/arquivos/2014/LA_03222.pdf.

Pachalski L, Rodrigues JC, Vieira IF, Miranda ARM. Os erros (orto)gráficos em textos de crianças do ciclo de alfabetização. II Congresso Brasileiro de Alfabetização; 2015a; Recife, PE, Brasil.

Pachalski L, Rodrigues JC, Vieira IF, Miranda ARM. Simetrias e assimetrias entre a aquisição da fala e da escrita: o uso da metátese como estratégia para a grafia do onset complexo. XXIV Congresso de Iniciação Científica da UFPel; 2015b; Pelotas, RS, Brasil. Disponível em: http://cti.ufpel.edu.br/siepe/arquivos/2015/LA_04474.pdf.

Pachalski L, Miranda ARM. A metátese na aquisição da escrita: regularidades e possíveis motivações. XXV Congresso de Iniciação Científica da UFPel; 2016; Pelotas, RS, Brasil. Disponível em: http:/ / cti.ufpel.edu.br/siepe/arquivos/2016/LA_04230.pdf.

Piaget JA. Epistemologia Genética. Petrópolis: Vozes; 1971.

Redmer CDS. Metátese e epêntese na aquisição da fonologia do PB: uma análise com base na teoria da otimidade [dissertação]. Pelotas: Escola de Educação, Universidade Católica de Pelotas; 2007.

Selkirk E. The syllable. In: Hulst H, Smith N, editores. The structure of phonological representations. Vol. 2. Dordrecht: Foris; 1982. p. 337-379.

Tenani LE. Segmentações não-convencionais e teorias fonológicas. Letras de Hoje. 2004;39(3):233244.

Zitzke BC. Uma análise da ocorrência de metáteses na fala de crianças em fase de aquisição de linguagem Porto Alegre: Instituto de Letras e Artes, Pontifícia Universidade Católica de Porto Alegre; 1998.

Zitzke BC. Um levantamento de metáteses na fala de crianças em fase de aquisição da linguagem. Letras de Hoje. 2001;36(3):219-227. 